\title{
An NCR1-based chimeric receptor endows T-cells with multiple anti-tumor specificities
}

\author{
Yair Tal ${ }^{1, *}$, Shlomo Yaakobi, ${ }^{1, *}$, Miryam Horovitz-Fried ${ }^{1}$, Einav Safyon ${ }^{1}$, Benyamin \\ Rosental'2, Angel Porgador ${ }^{2}$, Cyrille J. Cohen ${ }^{1}$ \\ ${ }^{1}$ Laboratory of Tumor Immunology and Immunotherapy, The Goodman Faculty of Life Sciences, Bar-Ilan University, Ramat \\ Gan 52900, Israel \\ 2 The Shraga Segal Department of Microbiology, Immunology and Genetics, and the National Institute for Biotechnology in \\ the Negev, Faculty of Health Sciences, Ben-Gurion University of the Negev, Beer-Sheva 84105, Israel \\ * These authors contributed equally to this study \\ Correspondence to: Cyrille J. Cohen, email: Cyrille.Cohen@biu.ac.il
}

Keywords: NCR1, Tumor Immunotherapy, T-cells, T-cell engineering

Received: February 20, $2014 \quad$ Accepted: April 24, $2014 \quad$ Published: April 24, 2014

This is an open-access article distributed under the terms of the Creative Commons Attribution License, which permits unrestricted use, distribution, and reproduction in any medium, provided the original author and source are credited.

\section{ABSTRACT:}

The Ral (Ras-like) GTP-binding proteins (RalA and RalB), as effectors of the proto-oncogene Natural killer (NK) cells are an important component of the antitumor response. Tumor recognition by NK cells was found to be partly triggered by molecules termed natural cytotoxic receptors (NCRs). Adoptive transfer of geneticallyengineered tumor-reactive T-lymphocytes can mediate remarkable tumor regressions mostly in melanoma and leukemia patients. Yet, the application of such treatments to other cancers is needed and dependent on the isolation of receptors that could facilitate efficient recognition of these malignancies. Herein, we aimed at combining NK tumor recognition capability with the genetic modification of T-cells to provide the latter with a means to recognize several tumors in a non-MHC restricted way.

Consequently, we generated and evaluated several chimeric receptors based on the extracellular domain of NCR1 (NKp46) fused to multiple signaling moieties and assess their antitumor activity when retrovirally expressed in T-cells. Following coculture with different tumors, primary human T-lymphocytes expressing a chimeric NCR1 molecule recognized target cells derived from lung, cervical carcinoma, leukemia and pancreatic cancer. In addition, this receptor mediated an upregulation of surface activation markers and significant antitumor cytotoxicity both in vitro and in vivo. These results have meaningful implications for the immunotherapeutic treatment of cancer using gene-modified T-cells.

\section{INTRODUCTION}

Tumor development and progression has often been reported to be associated with the lack of specific recognition of cancer cells by the immune system [1]. Natural killer (NK) cells are an important component of the anti-tumor response and their lytic capability depends on the integrated balance between activating and inhibitory signals [2;3]. Engagement of inhibitory receptors by MHC class I can prevent NK cell activation, thereby protecting the target cells from NK cell attack and thus, NK function is triggered in part by the recognition of "missing self" [4]. In addition, positive signals mediated by receptors are needed for full NK activation and tumor cell lysis [5]. Activating receptors include NKG2D, DNAM-1 and the natural cytotoxicity receptors (NCRs) family, the latter being composed of three molecules: NCR1 (NKp46), NCR-2 (NKp44) and NCR-3 (NKp30) [6]. NCR1 was the first NCR isolated and is a type I-transmembrane receptor that contains 2 Ig-domains and that associates with either CD3 $\zeta$ or FceRI $\gamma$ in order to signal $[7 ; 8]$. We and others showed that NCR1 is central to the recognition and lysis by NK cells of viral-infected and tumor cells such as carcinomas, neuroblastomas, and leukemias [9-16]. Though it has been demonstrated that heparan sulfate, which can be upregulated by cancer cells, can bind to NCR1 [17], the precise identification of the cellular ligands of NCR1 remains a challenge [6;18]. 
So far, the use of NK cells for immunotherapybased cancer treatments has been limited due in part to difficulties in expanding and properly conditioning these lymphocytes [19], poor reactivity in vivo using autologous approaches [20] and immune rejection in allogeneic settings $[21 ; 22]$. Conversely, the adoptive transfer of another type of tumor-reactive cells - T-lymphocytes - has been demonstrated to mediate the regression of large solid and hematological tumors in cancer patients [23;24]. In that regard, we and others have shown that it is possible to engineer lymphocytes to express T-cell receptors (TCRs) that confer novel anti-tumor activity directed against various types of cancer [25]. Still, the use of this therapeutic approach is limited to patients that express the appropriate $\mathrm{MHC}$ molecule to be recognized by the genetically introduced anti-tumor TCR. Provided the target antigen is expressed on the surface of the tumor cell, it is possible to circumvent this using chimeric receptors composed of a targeting moiety (usually an antibody fragment specific for a defined antigen) and a signaling portion (derived from CD3 $\zeta$ or FcRIII $\gamma$ molecules) [23]. However, these strategies are often directed at a specific antigen whose expression may be restricted to certain types of cancer.

Thus in the present study, we combined the therapeutic potential of gene-modified T-cells with the recognition pattern of NCR1 in order to devise a targeting strategy directed towards multiple tumors in a non-MHC restricted way. We designed and optimized an NCR1-based chimeric receptor. The latter endowed primary human T-cells with anti-tumor activity against various malignancies by means of cytokine secretion, upregulation of activation markers, improved expansion and cytotoxicity in vitro and in a mouse model.

\section{RESULTS}

\section{Construction and evaluation of NCR1-based chimeric receptors}

We generated various NCR1-based chimeric receptors by cloning out the cDNA encoding NCR1 from human NK-cells and by fusing its extracellular domain to different co-stimulatory/activating domains (Figure 1A). These and the wild-type NCR1 receptor (N1) were cloned into the pGEM-4Z/64A vector and we produced mRNA encoding these receptors which were expressed by electroporation into Jurkat cells. Twenty four hours after the electroporation, the expression of the different receptors was assessed by flow cytometry. As seen in Figure 1B, we were able to detect surface expression of all the introduced receptors, with $\mathrm{N} 1 / 28 \mathrm{z}$ and $\mathrm{N} 1 / 28 \mathrm{~g}$ exhibiting the highest levels with $81.1 \%(\mathrm{MFI}=10)$ and 83.6 (MFI=15) of positive cells respectively, compared to the mock-electroporated background.

We then tested the function of these receptors by electroporating mRNA encoding the latter into OKT3 -stimulated human primary lymphocytes. These cells were incubated with plate-bound anti-NCR1 and after $16 \mathrm{~h}$, we harvested the supernatant and measured IFN $\gamma$ concentrations by ELISA. Of all the receptors tested, we found that N1/28z mediated the highest secretion of IFN $\gamma$ compared to the unstimulated control (1565 vs. 30 $\mathrm{pg} / \mathrm{ml}$ ). Interestingly, whereas we observed a high level of surface expression for $\mathrm{N} 1 / 28 \mathrm{~g}$, the latter performed relatively poorly in functional assays, suggesting that surface expression might not always be predictive of the receptor function. We thus selected $\mathrm{N} 1 / 28 \mathrm{z}$ as our lead chimeric receptor for subsequent evaluation.

\section{$\mathrm{N} 1 / 28 \mathrm{z}$ mediates the recognition of tumors of different histologies.}

NCR1 has been shown to contribute to anti-tumor immunity $[10 ; 11 ; 15 ; 16]$. To test whether our chimeric receptor $\mathrm{N} 1 / 28 \mathrm{z}$ could mediate the recognition of tumors when expressed in primary human T-cells, we generated a retroviral construct based on the clinically-approved MSGV1 backbone and transduced primary human T-cells with retroviral supernatant encoding N1/28z or NGFR (control gene). These cells were stained with an anti-NCR1 antibody and analyzed by flow cytometry. As seen in Figure 2A, we achieved high levels of surface expression of the chimeric receptor $93.8 \%$ of positive cells with an MFI $=167$. These levels of expression were sustained for 30 days after transduction without selection and the growth and expansion of N1/28z-transduced cells was comparable to that of the NGFR-transduced population (data not shown).

Next, we assessed the antitumor function of the $\mathrm{N} 1 / 28 \mathrm{z}$ receptor and set up a co-culture of N1/28z- or NGFR- (control) transduced cells with several tumor lines of different histology that express NCR1-ligand (Suppl. Fig. 1). We detected specific cytokine secretion by N1/28z-expressing cells compared to the NGFRtransduced control group (e.g. $1456 \mathrm{pg} / \mathrm{ml}$ vs. $95 \mathrm{pg} / \mathrm{ml}$ of IFN $\gamma$ and 404 vs. $9 \mathrm{pg} / \mathrm{ml}$ of IL-2 respectively, in coculture with HeLa cells; $p<0.05-$ Fig. 2B). No significant cytokine secretion was observed in co-culture with NGFR expressing cells or in the presence of normal PBLs. Thus, $\mathrm{N} 1 / 28 \mathrm{z}$ can mediate the recognition of tumors of different histologies.

\section{Activation marker upregulation and cellular proliferation mediated by $\mathrm{N} 1 / 28 \mathrm{z}$}

To test whether this NCR-based chimeric receptor could trigger the upregulation of T-cell activation markers, 
N1/28z- or NGFR- transduced T-cells were co-cultured overnight with different tumor lines and analyzed for surface expression of activation markers (CD25 and CD69). Compared to the NGFR-cell population, N1/28zengineered cells demonstrated a statistically significant

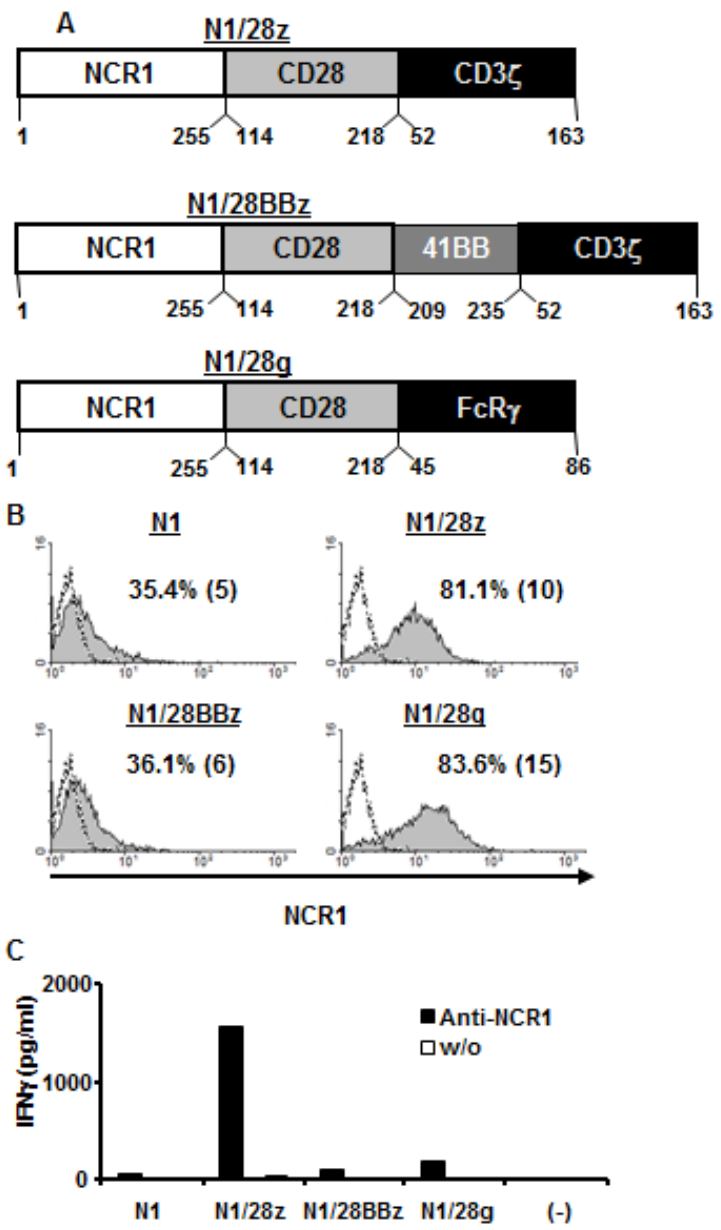

Figure 1: Design and expression of NCR1 chimeras. (A) - Schematic representation of the different NCR-1-based chimeric receptors. The amino acid numbering (based on the original protein) is indicated below each segment. (B) Jurkat RT3-T3.5 cells were electroporated with $2 \mu \mathrm{g}$ of mRNA encoding the wild-type NCR1 (N1) and its chimeric versions as indicated. NCR-1 expression was assessed by flow cytometry $24 \mathrm{~h}$ after electroporation. The dotted line represents the NCR1staining of the mock-electroporated control. The percentage of positive cells and the MFI (in brackets) are shown. These results are representative of 4 independent experiments and the difference between the population transduced with NCR1 chimeric molecules and the mock-electroporated population was found statistically significant $(\mathrm{p}<0.05$; calculated using a Student's paired t-test). (C) Human primary lymphocytes were electroporated with $2 \mu \mathrm{g}$ of mRNA encoding the different receptors as indicated. $10^{5}$ cells were incubated in a 96-well plate in the presence of plate-bound anti-NCR1 $(0.2 \mu \mathrm{g} /$ well $)$ for $16 \mathrm{~h}$. IFN $\gamma$ secreted in the co-culture supernatant was measured by ELISA. These results are representative of three independent experiments, performed with two different donors. superior expression of these markers (Fig. 3A - e.g.: 69.4\% $(\mathrm{MFI}=38)$ of CD25-positive cells and $62.8 \%(\mathrm{MFI}=48)$ of CD69-positive cells in co-cultures with K562 tumor targets).

We also assessed the capacity of N1/28z to facilitate

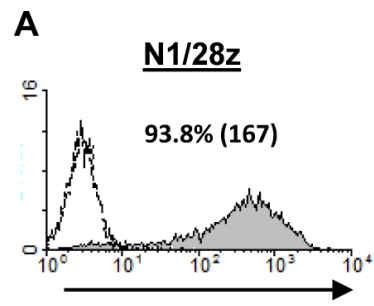

NCR-1

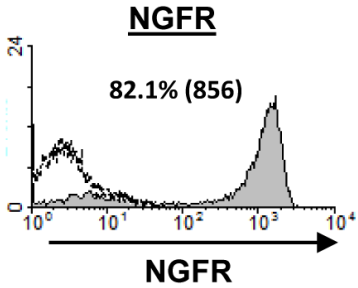

B
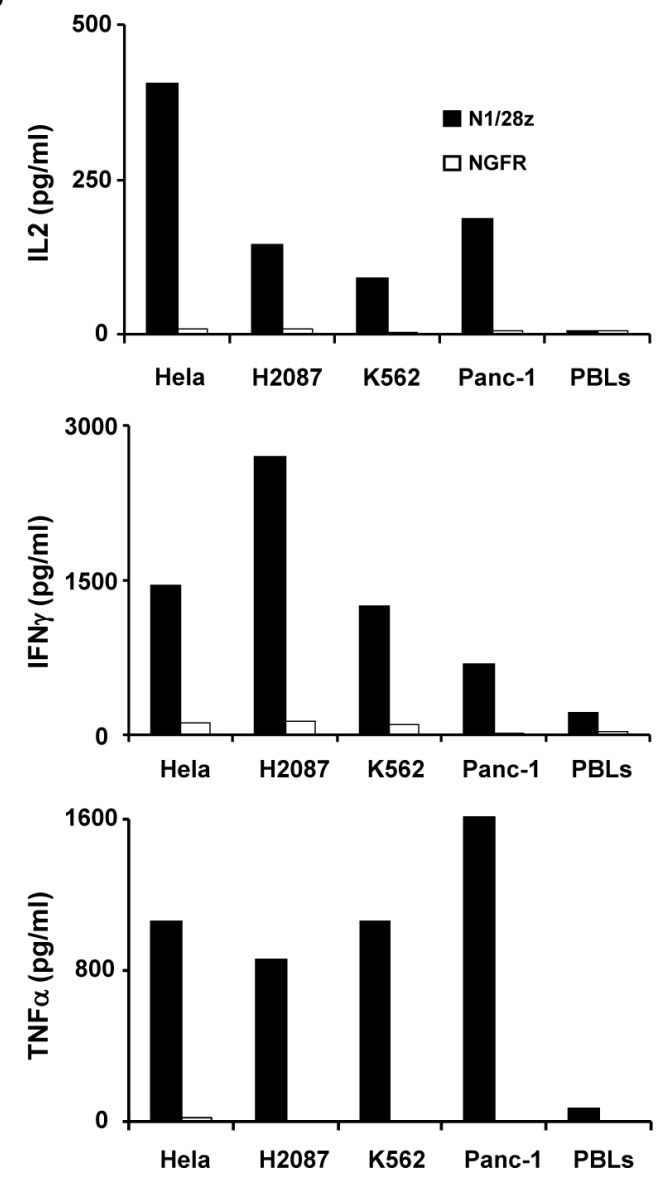

Figure 2: Anti-tumor function of the N1/28z chimera. (A) Human primary lymphocytes were transduced with a retroviral vector encoding either N1/28z or NGFR (control). Transduced T cells were analyzed for NCR 1 or NGFR expression $72 \mathrm{~h}$ after transduction by flow cytometry. The results are representative of 8 independent experiments performed with 6 different donors. (B) These cells were co-cultured with different tumor lines or normal PBLs as indicated. IL-2 (upper panel), IFN $\gamma($ middle panel) and TNF $\alpha$ (lower panel) secreted in the coculture supernatant was measured by ELISA. These results are representative of four independent experiments, performed with three different donors and the difference between the N1/28z and NGFR populations was found statistically significant $(\mathrm{p}<0.05$, calculated using a Student's paired t-test). 
cellular proliferation upon triggering of the receptor. To do so, activated human T-cells, transduced to express N1/28z or NGFR, were labeled with CFSE and cultured in the presence of plate-bound anti-NCR1 for 4 days. These cells
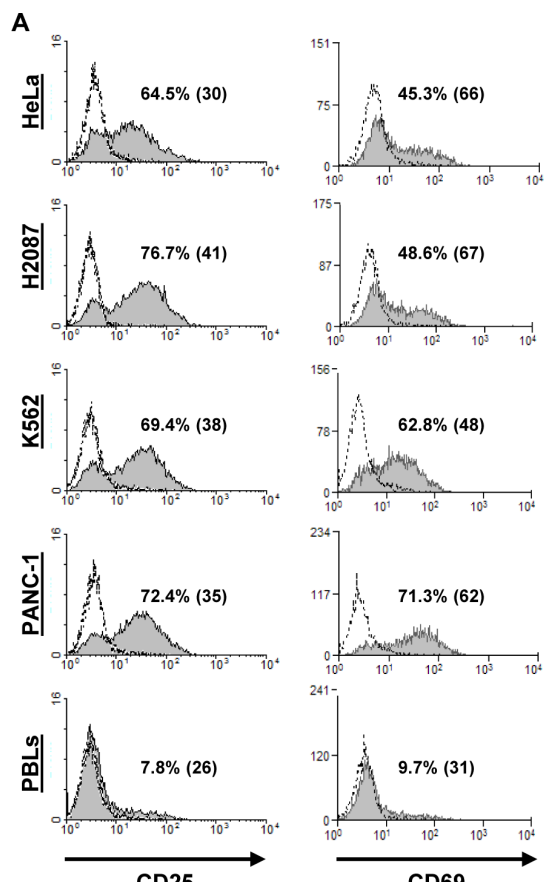

B
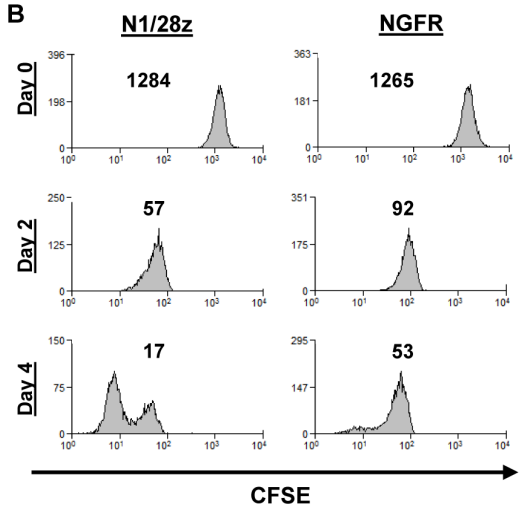

Figure 3: Activation marker upregulation and cell proliferation assay. (A) Transduced PBLs with either N1/28z or NGFR cells were co-cultured with tumor lines as indicated and analyzed by flow cytometry for marker expression gated on the $\mathrm{CD}^{+}$population (CD25 - left panels; CD69 - right panels). The percentage of positive cells and the MFI (in brackets) are shown and the dotted line represents the marker staining of the NGFR control. These results are representative of at least four independent experiments with at least three donors and the difference between N1/28z and NGFR was found to be statistically significant $(\mathrm{p}<0.05$, calculated using a Student's paired t-test). (B) Proliferation assay. CFSE-labeled activated transduced T-cells were stimulated with plate-bound anti-NCR1 ( $0.5 \mathrm{ug} /$ well). Two and 4 days after stimulation, the cells were analyzed for CFSE dilution. The MFI is shown at the different time points. These results are representative of three independent experiments with two donors and the difference between the two groups was found statistically significant $(\mathrm{p}<0.05$, calculated using a Student's paired t-test). were analyzed for CFSE dilution on day 2 and 4 after the beginning of the stimulation. As seen in Fig. 3B, N1/28zexpressing lymphocytes proliferated more as demonstrated by the lower MFI of the analyzed population compared to
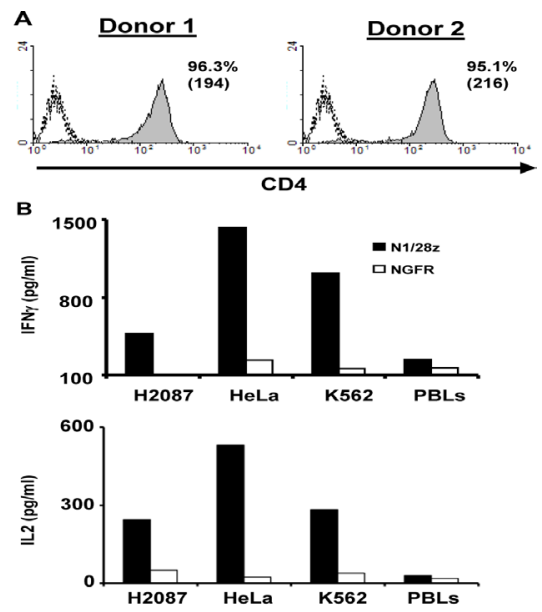

C
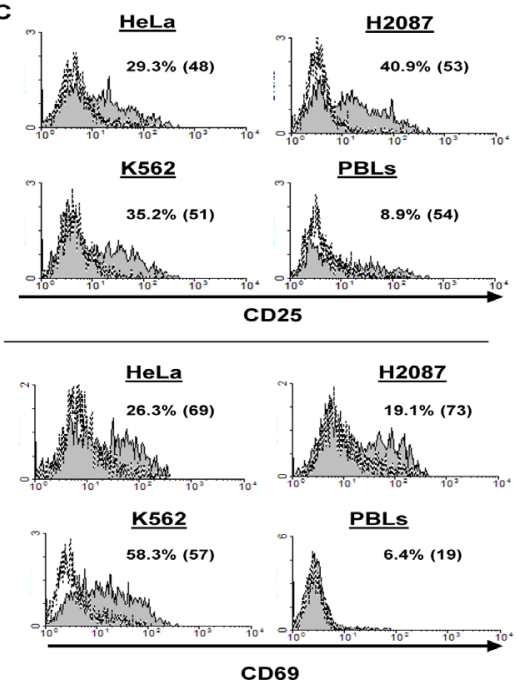

Figure 4: $\mathbf{N 1 / 2 8 z}$ function in $\mathrm{CD}^{+}$cells. (A) Human CD4+ cells were purified using a magnetic beads approach. The purity of the separated population was analyzed by flow cytometry for two donors. The dotted line represents the fluorescence of the unstained population. The percentage of $\mathrm{CD}^{+}$positive cells and the MFI (in brackets) are shown. (B) N1/28z- or NGFR-transduced CD4 ${ }^{+}$cells were co-cultured with different tumor lines or not as indicated. IFN $\gamma$ secreted in the coculture supernatant was measured by ELISA. These results are representative of three independent experiments, performed with three different donors and the difference between the N1/28z and NGFR populations was found statistically significant $(*: p<0.05$, calculated using a Student's paired t-test). (C) $\mathrm{CD} 4^{+}$-transduced $\mathrm{T}$ cells were analyzed by flow cytometry for marker expression (CD25 - upper panels; CD69 - lower panels) following overnight co-culture with tumor cells as indicated. The percentage of positive cells and the MFI (in brackets) are shown and the dotted line represents the marker staining of the NGFR control. These results are representative of three independent experiments with three donors and the difference between N1/28z and NGFR was found to be statistically significant $(\mathrm{p}<0.05$, calculated using a Student's paired t-test). 
NGFR-transduced cells (on day $2-\mathrm{MFI}=57$ vs. 97 and on day $4-\mathrm{MFI}=17$ vs. 53 respectively; $\mathrm{p}<0.05$ ).

In conclusion, $\mathrm{N} 1 / 28 \mathrm{z}$ can mediate the upregulation of activation markers and enhanced proliferation of transduced human T-lymphocytes.

\section{$\mathrm{N} 1 / 28 \mathrm{z}$ chimeric receptor can mediate $\mathrm{CD4}^{+}$ T-cells activation}

$\mathrm{CD}^{+} \mathrm{T}$-cell responses are essential to the full extent of the adaptive immune response. Unlike a classical T-cell receptor, the $\mathrm{N} 1 / 28 \mathrm{z}$ chimeric receptor is not $\mathrm{MHC}$ restricted, and thus we surmised it should function in $\mathrm{CD}^{+}$ $\mathrm{T}$ cells. To test this, we purified human primary $\mathrm{CD}^{+}$ cells (Fig. 4A) and transduced them with either N1/28z or NGFR. The cells were co-cultured with different tumor lines and analyzed for IFN $\gamma$ and IL-2 secretion as well as activation marker upregulation. As expected, N1/28z mediated a significant cytokine secretion by transduced lymphocytes compared to the NGFR control (IFN $\gamma$ - 1432 vs. $235 \mathrm{pg} / \mathrm{ml}$ and $1016 \mathrm{vs} .153 \mathrm{pg} / \mathrm{ml}$ in co-culture with HeLa and K562 respectively- Fig. 4B). Moreover, N1/28z caused an upregulation of the T-cell activation markers CD25 and CD69 as seen in Fig. 4C; e.g. 35.2\% of CD25and $58.3 \%$ of CD69-positive cells in co-culture with the $\mathrm{K} 562$ cell line. These data indicate that $\mathrm{N} 1 / 28 \mathrm{z}$ can endow CD4+ T-lymphocytes with anti-tumor function.

\section{Cytotoxicity in vitro and in vivo}

To ascertain the influence of the genetic modification of T-cells with $\mathrm{N} 1 / 28 \mathrm{z}$ on T-cell cytotoxic potential, we first performed cell-mediated cytotoxicity assays; following the co-culture of transduced $\mathrm{CD} 8^{+} \mathrm{T}$-cells with
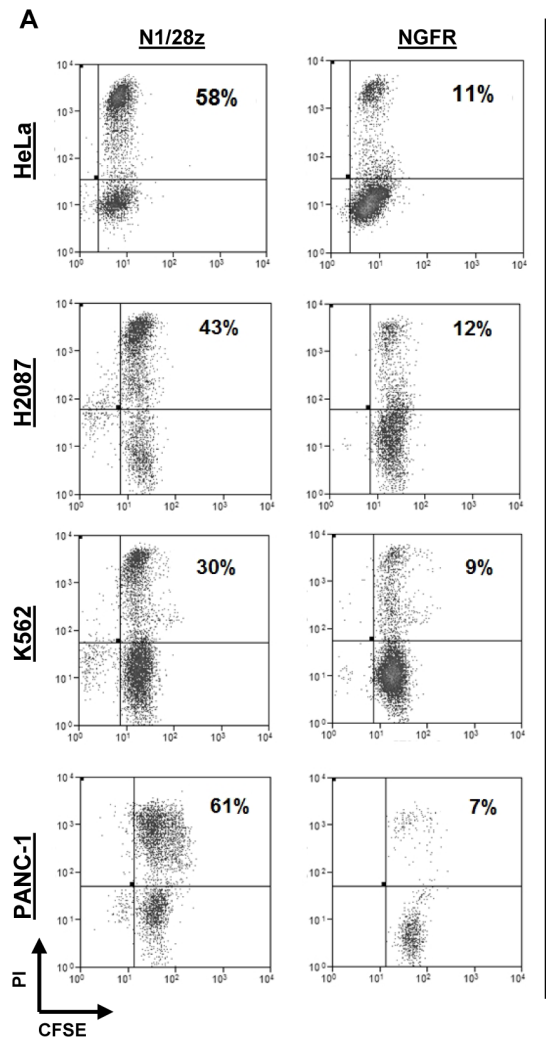

B
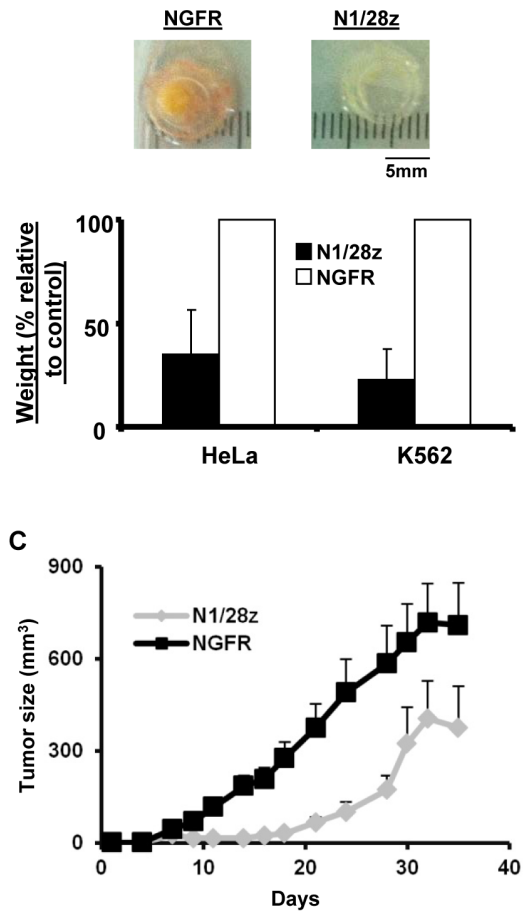

Figure 5: N1/28z mediates anti-tumor cytotoxic activity. (A) N1/28z- or NGFR-transduced cells were co-cultured with the indicated CFSE-labeled tumor cells at a ratio of 1:1 (E:T). After $18 \mathrm{~h}$, propidium iodide (PI) was added and the cells were analyzed by flow cytometry. The relative percentage of PI-positive cells (gated on the CFSE-labeled population - tumor cells) is shown. These results are representative of four independent experiments with two different donors and the difference between the N1/28z and NGFR populations was found statistically significant ( $\mathrm{p}<0.05$, calculated using a Student's paired t-test). (B) Tumors (derived from HeLa or K562 as indicated) that grew for five days on the CAM of chick embryo, were treated with adoptively transferred T-lymphocytes engineered to express either $\mathrm{N} 1 / 28 \mathrm{z}$ or NGFR (control). At $\mathrm{d}=5-6$ after treatment, the tumors were excised and weighed in a blinded manner. We show the percentage of the average tumor weight (+SEM) of the N1/28z-treated group relative to the NGFR-treated control group (100\%). These results were obtained with three different donors and the difference between the N1/28z and the NGFR- (control) groups was found statistically significant ( $\mathrm{n}=6 ; \mathrm{p}=0.005$, calculated using a Student's paired t-test). (C) Winn assay. Athymic nude mice were inoculated with HeLa cells and transduced lymphocytes (either N1/28z or NGFR -control as indicated) in the flank. Tumor growth was measured in a blinded fashion using a caliper and calculated using the following formula: $\left(\mathrm{Dxd}^{2}\right) \mathrm{x} \Pi / 6$, where $\mathrm{D}$ is the largest tumor diameter and $\mathrm{d}$ its perpendicular one. Results are shown for the different time points as mean+SEM of three separate experiments $(n=3)$ that included 6 mice each, and the difference between the N1/28z and NGFR-treated groups was found statistically significant $\left(\mathrm{p}=3 \times 10^{-5}\right)$. 
CFSE-labeled tumor cells, we observed a statistically significant anti-tumor cytotoxic activity mediated by N1/28z-transduced lymphocytes as exemplified by the PIpositive population (Fig. $5 \mathrm{~A}-58 \%$ for $\mathrm{N} 1 / 28 \mathrm{z}$ vs. $11 \%$ for NGFR using the HeLa target cell-line; $p=0.05$ ).

The anti-tumor activity of N1/28z transduced T-cells was further confirmed in an in ovo cytotoxicity assay we recently developed [29;30], based on xenograft model using the chick embryo chorioallantoic membrane (CAM) model. Following treatment with N1/28z-transduced T-cells, we observed striking regressions of established tumors compared to control groups treated with NGFRtransduced T-cells (Fig. 5B). The average weight for tumors treated was reduced by approximately $65 \%$ in the N1/28z treated tumors compared to the control treatment with NGFR cells $(n=6 ; p=0.005)$. Finally, we performed a Winn assay to test the ability of N1/28z-transduced T-cells to mediate enhanced anti-tumor activity in vivo. Nude mice were inoculated with a mixture of HeLa cells and N1/28z- or NGFR-transduced cells (at E:T of 2:1) and we followed tumor development in the subsequent weeks. As seen in Fig. 5C, the N1/28z treated group displayed a statistically significant reduced tumor growth compared to the NGFR (control) group $\left(\mathrm{p}=3 \times 10^{-5}\right)$. In conclusion, the chimeric receptor $\mathrm{N} 1 / 28 \mathrm{z}$ is able to mediate anti-tumor cytotoxicity both in in vitro and in vivo settings.

\section{DISCUSSION}

Chimeric antigen receptor therapy is a promising approach for the treatment of advanced cancer [23;31]. As NCR1 has been shown to contribute to anti-tumor immunity $[10 ; 11 ; 15 ; 16]$, in the present work we have explored the use of NCR1 as a targeting moiety to redirect T-cells anti-tumor activity against a panel of different malignancies. While this receptor can associate with $\mathrm{CD} 3 \zeta$ in order to signal [6] and recent studies suggest that certain T-cell subtypes can express NCR1 naturally (reviewed in Hudspeth et al. [8]), we did not observe a significant function mediated by the native NCR1 receptor when expressed in human primary T-cells (N1 receptorFig.1C). This lack of function might be partly explained by the need to compete with the T-cell receptor for CD3 molecules, the latter being considered a bottle-neck for TCR expression [32].

We designed several NCR1-based chimeric receptors and evaluated them in primary human T-cells. Whilst it has been argued that the inclusion of a 4-1BB signaling domain could improve T-cell function and prevent activation induced cell death [33;34], N1/28BBz showed a decreased stability (as suggested previously [31;35]) which apparently led to poor function (Fig.1C). Still, as the inclusion of co-stimulatory domains other than CD28 (e.g. OX40 [36] or CD27 [37]) may improve CARfunction, further optimization is warranted. In contrast, N1/28g which was expressed the most efficiently (Fig.
1B), failed to function (Fig. 1C) and this seems to be in agreement with previous observations [38;39]. Thus, the present results underscore the need to evaluate both the expression and the function of chimeric receptors empirically as previously advised [31;39].

After selecting an optimal construct, namely $\mathrm{N} 1 / 28 \mathrm{z}$, we expressed it in human primary T-cells and were able to target tumors of multiple origins. Such strategies aimed at targeting several malignancies using the same non-MHC restricted receptor [40-44] are attractive as they would provide an almost off-the-shelf "universal" reagent for the immunotherapeutic treatment of cancer. Unlike in NK cells in which NCR1 can be down-regulated in cancer patients $[45 ; 46]$ and its activity could be attenuated when exposed to tumor-expressed inhibitory ligands (such as MHC), T-cell expressing N1/28z could circumvent such an inhibition. On the other hand, since the nature of the cellular ligands of NCR1 is still a matter of intensive research [6], it will be important to include a suicide gene in the construct for potential clinical applications. As such, our in vivo assay (Fig. 5B) provides some preliminary insights into the therapeutic potential of the present approach.

As seen in Fig.4, N1/28z mediated also anti-tumor activity when expressed in $\mathrm{CD}^{+}$human primary T-cells. The possibility to recruit $\mathrm{CD} 4^{+} \mathrm{T}$ cells using an anti-tumor receptor is appealing as they may support CTL anti-tumor response [47]. However in clinical settings, one might need to utilize only selected helper T-cell populations such as Th1 and not Tregs or Th17 which have been shown respectively to hamper anti-tumor immunity or whose role in this context is unclear at the present.

It has been suggested that certain T-cell subtypes express NCRs as part of an original strategy to quickly respond to pathogens in a non-antigen specific manner [8]. In addition, we and others have shown that NCR1 may be central to the recognition and eradication of certain viral and bacterial infections [9;48-50]. Thus, we propose that our approach could be extended to the treatment of such infections using N1/28z redirected T-cells.

In conclusion, we have designed and optimized an NCR1-based chimeric receptor that enables the targeting of malignancies of diverse histology and we are confident that the development of such non-MHC restricted tumortargeting strategies will be beneficial to adoptive transfer treatments based on engineered T- lymphocytes.

\section{MATERIAL \& METHODS}

\section{PBMCs and cell lines}

All the PBMCs used in this study were from normal donors obtained from the Israeli Blood Bank (Sheba Medical Center, Tel-Hashomer, Israel). K562 (ATCC 
CCL-243) is an erythroleukemia cell line, H2087 (ATCC/ CRL-5922) is a non-small cell lung cancer cell line, HeLa (ATCC/CCL-2) is a cervix adenocarcinoma cell line and PANC-1 (ATCC/CRL1459) is a pancreatic cancer cell line. Viral packaging cell line 293GP, which stably expresses GAG and POL proteins has been previously described [26]. Adherent cells were cultured in DMEM (Invitrogen, Carlsbad, CA), supplemented with 10\% heatinactivated Fetal Bovine Serum (Biological Industries, Beth Haemek, Israel) and were maintained in a $37^{\circ} \mathrm{C}$ and $5 \% \mathrm{CO}_{2}$ incubator. Lymphocytes were cultured in BioTarget medium (Biological Industries, Beth Haemek, Israel) supplemented with $10 \%$ heat-inactivated FBS and $300 \mathrm{IU} / \mathrm{ml} \mathrm{IL-2}$ (Peprotech, Israel) and maintained at $37^{\circ} \mathrm{C}$ and $5 \% \mathrm{CO}_{2}$.

\section{NCR1 chimeras and retroviral constructs}

The cDNA encoding the human NCR1 was amplified from reverse-transcribed mRNA isolated from human NK cells. The different chimeras were created by overlapping PCR and their amino acid composition as indicated in Fig. 1A. These were cloned into the pGEM$4 \mathrm{Z} / 64 \mathrm{~A}$ vector which enables the in vitro generation of mRNA encoding the constructs as described previously [26;27]. The selected chimeric receptor, N1/28z as well as a truncated version of the long-nerve growth factor receptor (NGFR) were cloned into the well-characterized retroviral vector backbone pMSGV1 [28], which is a derivative of the MSCV-based splice-gag vector (pMSGV), and which uses a murine stem cell virus (MSCV) long terminal repeat.

\section{Electroporation of PBLs}

This technique has been extensively described in our previous reports [26;27]. Briefly, in vitro-transcribed mRNA for NCR-1 chimeric receptor was electroporated into OKT3-stimulated PBLs at $400 \mathrm{~V} / 500 \mu \mathrm{s}$ using an ElectroSquare Porator ECM 830 (BTX, San Diego, CA). The amount of in vitro-transcribed mRNA was $2 \mu \mathrm{g}$ per $1 \times 10^{6}$ PBMCs.

\section{Transduction of PBLs}

For virus production, transfection of $2 \times 10^{6} 293 \mathrm{GP}$ cells with $9 \mu \mathrm{g}$ DNA of MSGV1-based retroviral construct and $4.5 \mu \mathrm{g}$ envelop plasmid (VSV-G) was performed using JetPrime transfection reagent (Polyplus, France). Retroviral supernatant was collected $36 \mathrm{~h}$ after the DNA transfection. Freshly isolated human PBLs were stimulated for $48 \mathrm{~h}$ in the presence of $50 \mathrm{ng} / \mathrm{ml}$ OKT3 (eBioscience, San Diego, CA) before transduction. Following stimulation, lymphocytes were transduced with retroviral vectors by transfer to non-treated tissue culture dishes (Nunc, Rochester, NY) that had been pre-coated with RetroNectin (Takara, Japan) and retroviral vectors as previously described [26].

\section{FACS analysis and Antibodies}

Fluorophore-labeled anti-human CD8, CD25, CD69 and NGFR were purchased from BioLegend (San Diego, CA). Anti-NCR1 antibody was purchased from R\&D Systems (Minneapolis, MN). Immunofluorescence, analyzed as the relative log fluorescence of live cells, was measured using a CyAn-ADP flow cytometer (Beckman Coulter, Brea, CA). Approximately $1 \times 10^{4}$ to $1 \times 10^{5}$ cells were analyzed. Cells were stained in a FACS buffer made of PBS, $0.5 \%$ BSA, and $0.02 \%$ sodium azide.

\section{Cytokine release assays}

Lymphocyte cultures were tested for reactivity in cytokine release assays using commercially available ELISA kits for IL-2, IFN $\gamma$ and TNF $\alpha(R \& D$ Systems, Minneapolis, MN). For these assays, $1 \times 10^{5}$ responder cells (T-cells) and $1 \times 10^{5}$ stimulator cells (tumor cells) were incubated in a $0.2-\mathrm{ml}$ culture volume in individual wells of 96-well plates. Stimulator cells and responder cells were co-cultured for $18 \mathrm{~h}$. Cytokine secretion was measured in culture supernatants diluted to be in the linear range of the assay. As a control for $\mathrm{T}$ cell activity, we incubated the different T-cell cultures with PMA/Ionomycin at a concentration of $50 \mathrm{ng} / \mathrm{ml}$ and $1 \mu \mathrm{M}$ respectively.

\section{Cell proliferation assay}

$1 \times 10^{5}$ T-cells were labeled with $1 \mu \mathrm{M}$ CFSE (eBioscience, San Diego, CA) for $6 \mathrm{~min}$ and then cultured in 96-well plate in the presence of $0.5 \mu \mathrm{g} /$ well plate-bound anti-NCR1 antibody (R\&D systems, Minneapolis, MN). On day 2 and 4 after stimulation, cell fluorescence was analyzed by flow cytometry.

\section{Cell separation}

T-cell populations were separated using a magnetic beads-based approach for negative selection (EasySep ${ }^{\mathrm{TM}}$ - StemCell Technologies Inc., Canada).

\section{Cell Mediated Cytotoxicity Assay}

Target cells were labeled with $2 \mu \mathrm{M}$ CFSE (eBioscience, San Diego, CA) for $6 \mathrm{~min}$ and then cocultured with transduced lymphocytes at $37^{\circ} \mathrm{C}$ for 18 $\mathrm{h}$, at E:T ratio of 1:1. After the co-culture, propidium 
iodide (PI) $1 \mu \mathrm{M}$ (Sigma-Aldrich, Jerusalem, Israel) was added for assigning the ratio of cell death. Samples were analyzed by flow cytometry.

\section{Winn Assay}

Six weeks-old athymic nude-Foxn1nu female mice (Harlan, Jerusalem, Israel) were inoculated in the flank with a mixture of $10^{6} \mathrm{HeLa}$ cells and $2 \times 10^{6}$ transduced lymphocytes resuspended in $40 \mu \mathrm{l}$ Biotarget medium. Tumor size was measured every 3 days using a caliper in a blinded fashion. All the procedures were performed according to the guidelines of the university committee for animal welfare.

\section{ACKNOWLEDGMENTS}

This work was supported by the Israel Ministry of Health (\#3-7227), Israel Cancer Association (20100070 and 20112019) and the Rachel Hoffmann Fund for research. The flow cytometer apparatus was financed with the generous help of the Milstein foundation. We thank Dr. Rachel Levy-Drummer, head of the statistical unit in the Faculty of Life Sciences, Bar-Ilan University for her advice on statistical data processing and presentation.

\section{Disclosure of conflict of interest}

The authors declare that the research was conducted in the absence of any commercial or financial relationships that could be construed as a potential conflict of interest.

\section{REFERENCES}

1. Swann,JB, Smyth,MJ. Immune surveillance of tumors. J.Clin.Invest 2007. 117: 1137-1146.

2. Vivier,E, Tomasello,E, Baratin,M, Walzer,T, Ugolini,S. Functions of natural killer cells. Nat.Immunol. 2008. 9: 503-510.

3. Purdy,AK, Campbell,KS. Natural killer cells and cancer: regulation by the killer cell Ig-like receptors (KIR). Cancer Biol.Ther. 2009. 8: 2211-2220.

4. Karre,K, Ljunggren,HG, Piontek,G, Kiessling,R. Selective rejection of H-2-deficient lymphoma variants suggests alternative immune defence strategy. Nature 1986. 319: 675-678.

5. Moretta,A, Bottino,C, Vitale,M, Pende,D, Cantoni,C, Mingari,MC, Biassoni,R, Moretta,L. Activating receptors and coreceptors involved in human natural killer cellmediated cytolysis. Annu.Rev.Immunol. 2001. 19: 197-223.

6. Koch,J, Steinle,A, Watzl,C, Mandelboim,O. Activating natural cytotoxicity receptors of natural killer cells in cancer and infection. Trends Immunol. 2013. 34: 182-191.
7. Sivori,S, Vitale,M, Morelli,L, Sanseverino,L, Augugliaro, R, Bottino,C, Moretta,L, Moretta,A. p46, a novel natural killer cell-specific surface molecule that mediates cell activation. J.Exp.Med. 1997. 186: 1129-1136.

8. Hudspeth,K, Silva-Santos,B, Mavilio,D. Natural cytotoxicity receptors: broader expression patterns and functions in innate and adaptive immune cells. Front Immunol. 2013. 4: 69.

9. Mandelboim,O, Lieberman,N, Lev,M, Paul,L, Arnon,TI, Bushkin,Y, Davis,DM, Strominger,JL, Yewdell,JW, Porgador,A. Recognition of haemagglutinins on virusinfected cells by NKp46 activates lysis by human NK cells. Nature 2001. 409: 1055-1060.

10. Glasner,A, Ghadially,H, Gur,C, Stanietsky,N, Tsukerman,P, Enk,J, Mandelboim,O. Recognition and prevention of tumor metastasis by the NK receptor NKp46/NCR1. J.Immunol. 2012. 188: 2509-2515.

11. Lakshmikanth,T, Burke,S, Ali,TH, Kimpfler,S, Ursini,F, Ruggeri,L, Capanni,M et al. NCRs and DNAM-1 mediate NK cell recognition and lysis of human and mouse melanoma cell lines in vitro and in vivo. J.Clin.Invest 2009. 119: $1251-1263$.

12. Sivori,S, Parolini,S, Marcenaro,E, Castriconi,R, Pende,D, Millo,R, Moretta,A. Involvement of natural cytotoxicity receptors in human natural killer cell-mediated lysis of neuroblastoma and glioblastoma cell lines. J.Neuroimmunol. 2000. 107: 220-225.

13. Nowbakht,P, Ionescu,MC, Rohner,A, Kalberer,CP, Rossy,E, Mori,L, Cosman,D, De Libero,G, WodnarFilipowicz,A. Ligands for natural killer cell-activating receptors are expressed upon the maturation of normal myelomonocytic cells but at low levels in acute myeloid leukemias. Blood 2005. 105: 3615-3622.

14. Elboim,M, Gazit,R, Gur,C, Ghadially,H, Betser-Cohen,G, Mandelboim,O. Tumor immunoediting by NKp46. J.Immunol. 2010. 184: 5637-5644.

15. Halfteck,GG, Elboim,M, Gur,C, Achdout,H, Ghadially,H, Mandelboim,O. Enhanced in vivo growth of lymphoma tumors in the absence of the NK-activating receptor NKp46/ NCR1. J.Immunol. 2009. 182: 2221-2230.

16. Wai,LE, Garcia,JA, Martinez,OM, Krams,SM. Distinct roles for the NK cell-activating receptors in mediating interactions with dendritic cells and tumor cells. J.Immunol. 2011. 186: 222-229.

17. Hecht,ML, Rosental,B, Horlacher,T, Hershkovitz,O, De Paz,JL, Noti,C, Schauer,S, Porgador,A, Seeberger,PH. Natural cytotoxicity receptors NKp30, NKp44 and NKp46 bind to different heparan sulfate/heparin sequences. J.Proteome.Res. 2009. 8: 712-720.

18. Bottino,C, Castriconi,R, Moretta,L, Moretta,A. Cellular ligands of activating NK receptors. Trends Immunol. 2005. 26: 221-226.

19. Ni,J, Miller,M, Stojanovic,A, Cerwenka,A. Toward the next generation of NK cell-based adoptive cancer 
immunotherapy. Oncoimmunology. 2013. 2: e23811.

20. Parkhurst,MR, Riley,JP, Dudley,ME, Rosenberg,SA. Adoptive transfer of autologous natural killer cells leads to high levels of circulating natural killer cells but does not mediate tumor regression. Clin.Cancer Res. 2011. 17: 62876297.

21. Lundqvist,A, McCoy,JP, Samsel,L, Childs, R. Reduction of GVHD and enhanced antitumor effects after adoptive infusion of alloreactive Ly49-mismatched NK cells from MHC-matched donors. Blood 2007. 109: 3603-3606.

22. Cheng,M, Chen, Y, Xiao,W, Sun,R, Tian,Z. NK cell-based immunotherapy for malignant diseases. Cell Mol.Immunol. 2013. 10: 230-252.

23. Merhavi-Shoham,E, Haga-Friedman,A, Cohen,CJ. Genetically modulating T-cell function to target cancer. Semin.Cancer Biol. 2012. 22: 14-22.

24. Restifo,NP, Dudley,ME, Rosenberg,SA. Adoptive immunotherapy for cancer: harnessing the $\mathrm{T}$ cell response. Nat.Rev.Immunol. 2012. 12: 269-281.

25. Daniel-Meshulam,I, Ya'acobi,S, Ankri,C, Cohen,CJ. How (specific) would like your T-cells today? Generating T-cell therapeutic function through TCR-gene transfer. Frontiers in Immunology 2012. 3: 186.

26. Haga-Friedman,A, Horovitz-Fried,M, Cohen,CJ. Incorporation of Transmembrane Hydrophobic Mutations in the TCR Enhance Its Surface Expression and T Cell Functional Avidity. J.Immunol. 2012. 188: 5538-5546.

27. Bialer,G, Horovitz-Fried,M, Ya'acobi,S, Morgan,RA, Cohen,CJ. Selected murine residues endow human TCR with enhanced tumor recognition. J.Immunol. 2010. 184: 6232-6241.

28. Morgan,RA, Dudley,ME, Wunderlich,JR, Hughes,MS, Yang,JC, Sherry,RM, Royal,RE et al. Cancer regression in patients after transfer of genetically engineered lymphocytes. Science 2006. 314: 126-129.

29. Daniel-Meshulam,I, Horovitz-Fried,M, Cohen,CJ. Enhanced anti-tumor activity mediated by human 4-1BBengineered T-cells. Int.J.Cancer 2013. DOI: 10.1002/ ijc. 28320 .

30. Ankri,C, Shamalov,K, Horovitz-Fried,M, Mauer,S, Cohen,CJ. Human $\mathrm{T}$ cells engineered to express a programmed death $1 / 28$ costimulatory retargeting molecule display enhanced antitumor activity. J.Immunol. 2013. 191: 4121-4129.

31. Gilham,DE, Debets,R, Pule,M, Hawkins, RE, Abken,H. CAR-T cells and solid tumors: tuning T cells to challenge an inveterate foe. Trends Mol.Med. 2012. 18: 377-384.

32. Ahmadi,M, King,JW, Xue,SA, Voisine,C, Holler,A, Wright,GP, Waxman,J, Morris,E, Stauss,HJ. CD3 limits the efficacy of TCR gene therapy in vivo. Blood 2011. 118: 3528-3537.

33. Carpenito,C, Milone,MC, Hassan, R, Simonet,JC, Lakhal,M, Suhoski,MM, Varela-Rohena,A et al. Control of large, established tumor xenografts with genetically retargeted human T cells containing CD28 and CD137 domains. Proc. Natl.Acad.Sci.U.S.A 2009. 106: 3360-3365.

34. Milone,MC, Fish,JD, Carpenito, C, Carroll,RG, Binder,GK, Teachey,D, Samanta,M et al. Chimeric receptors containing CD137 signal transduction domains mediate enhanced survival of $\mathrm{T}$ cells and increased antileukemic efficacy in vivo. Mol.Ther. 2009. 17: 1453-1464.

35. Zhao,Y, Wang,QJ, Yang,S, Kochenderfer,JN, Zheng,Z, Zhong,X, Sadelain,M, Eshhar,Z, Rosenberg,SA, Morgan,RA. A herceptin-based chimeric antigen receptor with modified signaling domains leads to enhanced survival of transduced $\mathrm{T}$ lymphocytes and antitumor activity. J.Immunol. 2009. 183: 5563-5574.

36. Hombach,AA, Heiders,J, Foppe,M, Chmielewski,M, Abken,H. OX40 costimulation by a chimeric antigen receptor abrogates CD28 and IL-2 induced IL-10 secretion by redirected CD4(+) T cells. Oncoimmunology. 2012. 1: 458-466.

37. Song,DG, Ye,Q, Poussin,M, Harms,GM, Figini,M, Powell,DJ, Jr. CD27 costimulation augments the survival and antitumor activity of redirected human T cells in vivo. Blood 2012. 119: 696-706.

38. Haynes,NM, Snook,MB, Trapani,JA, Cerruti,L, Jane,SM, Smyth,MJ, Darcy,PK. Redirecting mouse CTL against colon carcinoma: superior signaling efficacy of singlechain variable domain chimeras containing TCR-zeta vs Fc epsilon RI-gamma. J.Immunol. 2001. 166: 182-187.

39. Cartellieri,M, Bachmann,M, Feldmann,A, Bippes,C, Stamova,S, Wehner,R, Temme,A, Schmitz,M. Chimeric antigen receptor-engineered T cells for immunotherapy of cancer. J.Biomed.Biotechnol. 2010. 2010: 956304.

40. Sentman,CL, Barber,MA, Barber,A, Zhang,T. NK cell receptors as tools in cancer immunotherapy. Adv.Cancer Res. 2006. 95: 249-292.

41. Barber,A, Rynda,A, Sentman,CL. Chimeric NKG2D expressing $\mathrm{T}$ cells eliminate immunosuppression and activate immunity within the ovarian tumor microenvironment. J.Immunol. 2009. 183: 6939-6947.

42. Barber,A, Meehan,KR, Sentman,CL. Treatment of multiple myeloma with adoptively transferred chimeric NKG2D receptor-expressing T cells. Gene Ther. 2011. 18: 509-516.

43. Zhang, T, Wu,MR, Sentman,CL. An NKp30-based chimeric antigen receptor promotes $\mathrm{T}$ cell effector functions and antitumor efficacy in vivo. J.Immunol. 2012. 189: 22902299.

44. Marcu-Malina, V, Heijhuurs, S, van Buuren,M, Hartkamp,L, Strand,S, Sebestyen,Z, Scholten,K, Martens,A, Kuball,J. Redirecting alphabeta $\mathrm{T}$ cells against cancer cells by transfer of a broadly tumor-reactive gammadeltaT-cell receptor. Blood 2011. 118: 50-59.

45. Garcia-Iglesias, T, Toro-Arreola,A, Albarran-Somoza,B, Toro-Arreola,S, Sanchez-Hernandez,PE, RamirezDuenas,MG, Balderas-Pena,LM, Bravo-Cuellar,A, OrtizLazareno,PC, Daneri-Navarro,A. Low NKp30, NKp46 and 
NKG2D expression and reduced cytotoxic activity on NK cells in cervical cancer and precursor lesions. BMC.Cancer 2009. 9: 186.

46. Fauriat,C, Just-Landi,S, Mallet,F, Arnoulet,C, Sainty,D, Olive,D, Costello,RT. Deficient expression of NCR in NK cells from acute myeloid leukemia: Evolution during leukemia treatment and impact of leukemia cells in NCRdull phenotype induction. Blood 2007. 109: 323-330.

47. Muranski,P, Restifo,NP. Adoptive immunotherapy of cancer using CD4(+) T cells. Curr.Opin.Immunol. 2009. 21: 200-208.

48. Elhaik-Goldman,S, Kafka,D, Yossef,R, Hadad,U, Elkabets,M, Vallon-Eberhard,A, Hulihel,L et al. The natural cytotoxicity receptor 1 contribution to early clearance of Streptococcus pneumoniae and to natural killer-macrophage cross talk. PLoS.One. 2011. 6: e23472.

49. Gazit,R, Gruda,R, Elboim,M, Arnon,TI, Katz,G, Achdout,H, Hanna,J et al. Lethal influenza infection in the absence of the natural killer cell receptor gene Ncr1. Nat. Immunol. 2006. 7: 517-523.

50. Magri,G, Muntasell,A, Romo,N, Saez-Borderias,A, Pende,D, Geraghty,DE, Hengel,H, Angulo,A, Moretta,A, Lopez-Botet,M. NKp46 and DNAM-1 NK-cell receptors drive the response to human cytomegalovirus-infected myeloid dendritic cells overcoming viral immune evasion strategies. Blood 2011. 117: 848-856. 